\title{
Influence of Obesity in Mortality in Hospitalized Adults with Type 2 Diabetes
}

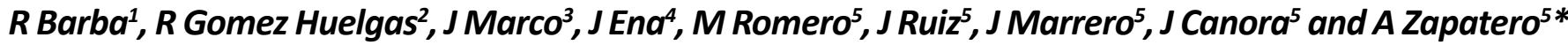 \\ ${ }^{1}$ Department of Internal Medicine, Hospital Rey Juan Carlos, Spain \\ ${ }^{2}$ Department of Internal Medicine, Hospital Universitario Regional de Malaga, Spain \\ ${ }^{3}$ Department of Internal Medicine, Hospital Clínico Universitario San Carlos, Spain \\ ${ }^{4}$ Department of Internal Medicine, Hospital Marina Baixa, Spain \\ ${ }^{5}$ Department of Internal Medicine, Hospital Universitario de Fuenlabrada, Spain
}

*Corresponding author: Antonio Zapatero Gaviria, MD, PhD, Department of Internal Medicine, Hospital Universitario de Fuenlabrada, Spain, E-mail: antonio.zapatero@salud.madrid.org

\begin{abstract}
Background: The aim of the present study is to assess the association between obesity and mortality in hospitalized patients with type 2 Diabetes Mellitus (T2DM) as well as the risk of readmission in less than 30 days.

Methods: A retrospective chart review of a cohort of consecutive patients admitted with T2DM in internal medicine wards in Spain between January $1^{\text {st }}, 2005$, and December $31^{\text {st }}$, 2013, was performed. Patients with a diagnosis of obesity were identified. The mortality and readmittance indexes of obese patients were compared with the subpopulation without theses diagnosis.

Results: A total of $1,499,282$ admittances were analyzed and $199,871(13.3 \%)$ diagnosis of obesity were identified. Obese patients showed a lower in-hospital mortality risk (odds ratio [OR], 0.667; 95\% confidence interval [Cl], $0.647-0.675$ ) and early re-admittance risk (OR, 0.96; 95\% $\mathrm{Cl}, 0.94-0.97)$ than the non-obese even after adjusting for possible confounding factors.

Conclusions: Obesity in those hospitalized for T2DM in internal medicine wards is associated with reduced inhospital mortality risk, early re-admittance and shorter length of stay.
\end{abstract}

\section{Introduction}

Overweight and obesity increase overall mortality and predict premature death (7-10). Furthermore, obesity is associated with the development of cardiovascular risk factors like increased insulin resistance and type 2 diabetes mellitus (T2DM), hypertension and dyslipidemia [1-3].

The association between obesity and increased risk for cardiovascular disease (CVD) is well-established in the general population $[4,5]$. Paradoxically, once CVD occurs, obesity seems to confer a survival advantage. There is growing evidence that overweight patients with CVD survive longer than their normal weight counterparts, an effect called the "obesity paradox".

Nevertheless, in a range of cardiovascular conditions such as heart failure $[6,7]$, stroke $[8,9]$, coronary heart disease survivors [10], as well as patients in chronic hemodialysis [11], renal failure [12], chronic obstructive pulmonary disease (COPD) $[13,14]$, cancer [15] and rheumatoid arthritis [16], an "obesity paradox "has been raised. Specifically, the prognosis of overweight and obese individuals seemed to be better than the prognosis of normal or low-weight subjects.

A similar obesity paradox might exist after type 2 diabetes has developed. In two contemporary studies, the Translating Research Into Action for Diabetes (TRIAD) study [17] and the Proactive trial [18] participants with diabetes who were normal weight at the baseline examination or who lost weight during the trial (PROactive) experienced higher mortality than participants who were overweight or obese. in Hospitalized Adults with Type 2 Diabetes. Int J Diabetes Clin Res 4:069. doi.org/10.23937/23773634/1410069

Received: January 18, 2017: Accepted: April 25, 2017: Published: April 27, 2017

Copyright: (C 2017 Barba R, et al. This is an open-access article distributed under the terms of the Creative Commons Attribution License, which permits unrestricted use, distribution, and reproduction in any medium, provided the original author and source are credited. 
Different studies have been published investigating the relationship between obesity (mostly defined by BMI) and mortality in type 2 diabetes. The results are inconsistent and contradictory. The majority of them reported an increase in mortality in obese patients with type 2 diabetes, with a U-shaped relationship (increased risk at lower and higher BMIs) [19-26]. In contrast, other studies showed that being overweight or obese was associated with better overall survival rates [17,27-29]. All these studies investigated the relationship between obesity and mortality in the follow up of type 2 diabetes mellitus patients.

However, few studies have analyzed the effect of obesity in in-hospital outcomes. While higher BMI may confer an advantage against mortality in the critical patient [30] and medical inpatients [31], in surgical populations mixed results have been reported [32,33].

Specifically, it is not well known if obesity modifies the in-hospital prognosis of diabetic patients. A recent study [34] has explored the impact of BMI and hyperglycemia on mortality and complications in hospitalized patients without showing the presence of an obesity paradox among diabetic inpatients.

The present study aims to investigate the association between obesity and mortality in medical patients hospitalized with T2DM, the length of stay and the risk of readmission in the next 30 days after discharge. The use of a large contemporary database has allowed closer examination of any graded association between obesity and mortality than among smaller studies.

\section{Methods}

We identified every patient discharged from Internal Medicine Departments among hospitals of the Spanish Public Health Service between January $1^{\text {st }}, 2005$ and December $31^{\text {st }}, 2013$. Hospitals discharge data were obtained from the BMDS (Basic Minimum Data Set). BMDS contains socio-demographic and clinical data for each documented hospital admission including: gender and age, primary and secondary diagnoses (according to the International Classification of Diseases, Ninth Revision, Clinical Modification (ICD-9-CM) code); primary and secondary procedures; admission and discharge status; length of stay, and hospital characteristics (group 1: less than 150 beds; group 2: 150 to 200 beds; group 3: 200 to 500 beds; group 4: 500 to 1,000 beds; group 5: more than 1,000 beds). For every patient, a diagnosisrelated group (DRG) was identified. DRGs are a method of classifying patient hospitalizations by diagnosis and procedures on the assumption that similar costs are expended on patients by using similar resources. The $\mathrm{CMBD}$ registry is compulsory for every patient admitted to a hospital of the Spanish National Health Service, a system that cares for more than $90 \%$ of the country's population.
Cases were selected if they had a diagnosis of diabetes. The diagnosis of diabetes was identified using ICD-9-MC codes 250.00-250.99 in the diagnosis field. Patients who had a secondary diagnosis of obesity (ICD9-CM: 278.00-278.02) were analyzed.

The standardized definition of the variable readmission in the Spanish CMBD has been defined as a new hospitalization in the following month with the same Major Diagnostic Category in the main diagnosis.

The Age Adjusted Charlson Co-morbidity Index (CCI) was computed for each patient. This index reflects the number and importance of comorbid diseases, relies on ICD-9-CM categories, and was used to adequately adjust for severity of illness $[35,36]$.

The following risk factors were identified using ICD9-MC codes in any primary or secondary diagnosis field: Tobacco: ICD-9-CM 305.10, Hypertension: ICD-9-CM 401.0, 401.1, 401.9, Acute myocardial infarct: ICD-9CM 410.xx, 412, Heart failure: ICD-9-CM 398.91, 404*, 402.11, 402.91, 428-428.9, Cerebrovascular disease: ICD-9-MC 430.00-438.99, COPD: ICD-9-CM 416.8, 416.9, 500-505, 490-496, Liver disease: ICD-9-CM 571.0571.99, Diabetes decompensation: ICD-9-CM 250.32, $250.33,250.42,250.43,250.52,250.53,250.62,250.63$, $250.72,250.73,250.82,250.82,250.92,250.93$, Kidney Chronic disease: ICD-9-CM 585.00-586.99, 582.00582.9, 583.00-583.7, 588.0-588.9, Neoplasia: ICD-9CM 140.0-172.9, 174.0-195.8, 200-208.9, Malnutrition: ICD-9-CM 260-263.9, Pressure ulcer: ICD-9-CM 707. $x x$, Urinary tract infection: ICD-9-CM 599.00, 590.xx, 646.60-49, 601.

\section{Data Analysis}

A descriptive analysis of these patients was carried out, and the demographic variables among the patients diagnosed with or without obesity were compared. We used the chi-square test for categorical variables with the Yates correction, the Fisher's exact test for dichotomous variables when the expected value of a cell was less than 5, and Student's t-test or ANOVA for quantitative variables. All the univariate analyses were carried out after adjusting for age and gender. The Odds-Ratios (OR) and $95 \%$ Confidence Intervals $(\mathrm{Cl})$ were estimated from the regression coefficients.

As this is an administrative database, the control of the confounding variables is basic. For this reason, a multivariate logistic regression analysis was carried out with the aim of determining the excess of mortality attributable to obesity, after the correction of possible confounding variables such as the age of the patient (in years, as a continuous variable), Charlson index (in points, as a continuous variable), sex and all variables that had demonstrated a statistically significant relation in the univariate analysis with mortality and are no included in the Charlson index. A logistic regression 
analysis with backward stepwise procedure and $p$ $>0.10$ as the criterion for exclusion, was used to find the best predictive models. Stratified analyses were performed to examine confounders and interactions were appropriate. All statistical analyses were carried out with the use of a SPSS Software version 16 (Chicago, Illinois, SPSS Inc).

\section{Results}

We identified 1,499,252 discharges with T2DM diagnosis during the study period. A total of 199,871 $(13.3 \%)$ subjects were obese. The main characteristics in obese and non-obese patients of our series are listed in Table 1. Compared with non-obese, obese patients were more frequently women (62.6\% versus $47.8 \%$ P.001), younger (71.87 versus 76.33 P.001), more frequently smokers (9.1\% versus $7.3 \%$ P.001).

Comorbid conditions were common and are listed in Table 1. Obese patients had more frequently hypertension, heart failure, chronic obstructive pulmonary disease, diabetes decompensation and kidney chronic disease. Non obese had more frequently acute myocardial infar- ction, dementia, cerebrovascular disease, liver disease, neoplasia, and malnutrition, pressure ulcers, urinary tract infection, Charlson $>2$, in-hospital mortality, longer admission stay and readmission $<30$ days.

A multivariable logistic regression analysis was performed showing that obese patients had a $34 \%$ lower risk of mortality than non-obese patients, after adjusting for potential confounding factors $(\mathrm{OR}, 0.667 ; 95 \% \mathrm{Cl}$, 0.647-0.675 (Table 2). In addition, the risk of readmission was linked to increasing age, $\mathrm{CCl}$, and gender, and obese patients were less likely to be readmitted (OR, 0.96; 95\% $\mathrm{Cl}$, 0.94-0.97; Table 2).

\section{Discussion}

The present study shows that obese T2DM patients had a significantly lower mortality during hospitalization and a lower risk of readmission in the next 30 days after discharge. The risk of mortality is lower in obese patients by $34 \%$ and of readmission at 30 days by $4 \%$. Length of stay was also shorter in obese T2DM patients than in non-obese (9.15 days vs. 9.66; $p<0,001$ ).

Our study includes a great number of patients

Table 1: Risk factors and baseline characteristics of 1,499,282 type 2 diabetes mellitus patients according to obesity or non obesity.

\begin{tabular}{|c|c|c|c|}
\hline Characteristics & Obese $(199,871)$ & Non obese $(1,299,411)$ & $P$ value \\
\hline Age, mean (SD) yr & $71,87(11.4)$ & $76,33(11.7)$ & $<0.001$ \\
\hline Gender (female) & $125,155(62.6 \%)$ & $621,314(47.8 \%)$ & $<0.001$ \\
\hline Smoking & $18,120(9.1 \%)$ & $95,506(7.3 \%)$ & $<0.001$ \\
\hline Hypertension & $125,102(62.6 \%)$ & $740,589(57 \%)$ & $<0.001$ \\
\hline Acute myocardial infarction & $9,329(4.7 \%)$ & $69,149(5.35)$ & $<0.001$ \\
\hline Heart failure & $42,332(21.2 \%)$ & $198,736(15.3 \%)$ & $<0.001$ \\
\hline Dementia & $3,654(1.8 \%)$ & $69,726(5.4 \%)$ & $<0.001$ \\
\hline Cerebrovascular disease & $13,224(6.6 \%)$ & $130,493(10.0 \%)$ & $<0.001$ \\
\hline COPD & $56,100(28.1 \%)$ & $294,298(22.6 \%)$ & $<0.001$ \\
\hline Liver disease & $3,061(1.5 \%)$ & $37,250(2.9 \%)$ & $<0.001$ \\
\hline Diabetic decompensation & $22,967(11.5 \%)$ & $122,194(9.4 \%)$ & $<0.001$ \\
\hline Kidney chronic disease & $34,116(17.1 \%)$ & $217,663(16.8 \%)$ & $<0.001$ \\
\hline Neoplasia & $6,028(3.0 \%)$ & $78,163(6.0 \%)$ & $<0.001$ \\
\hline Malnutrition & $1,161(0.6 \%)$ & $22,624(1.7 \%)$ & $<0.001$ \\
\hline Pressure ulcer & $2,497(1.2 \%)$ & $38,667(3.0 \%)$ & $<0.001$ \\
\hline Urinary tract infection & $18,984(9.5 \%)$ & $166,890(12.8 \%)$ & $<0.001$ \\
\hline Charlson $>2$ & $64,843(32.4 \%)$ & $462,282(35.6 \%)$ & $<0.001$ \\
\hline Mortality & $10,916(5.5 \%)$ & $133,251(10.3 \%)$ & $<0.001$ \\
\hline Length of stay, mean (SD), days & $9,15(8.5)$ & $9,66(10.2)$ & $<0.001$ \\
\hline Readmission (< 30 days) & $27,083(14.6 \%)$ & $191,131(16 \%)$ & $<0.001$ \\
\hline
\end{tabular}

Table 2: Multivariate analysis evaluating the association between obesity and clinical outcomes.

\begin{tabular}{|c|c|c|c|}
\hline Characteristics & OR & $95 \% \mathrm{Cl}$ & $P$ value \\
\hline \multicolumn{4}{|c|}{ Inpatient mortality } \\
\hline Age (10 yr) & 1.058 & 1.057-1.059 & $<0.001$ \\
\hline Gender (female) & 1.007 & 0.995-1.019 & 0.238 \\
\hline Charlson > 2 & 1.228 & $1.225-12231$ & $<0.001$ \\
\hline Obesity & 0.667 & $0.647-0.675$ & $<0.001$ \\
\hline \multicolumn{4}{|l|}{ Readmission } \\
\hline Age (10 yr) & 1.064 & $1.060-1.068$ & $<0.001$ \\
\hline Gender & 0.927 & $0.918-0.936$ & $<0.001$ \\
\hline Charlson > 2 & 1.136 & $1.133-1.139$ & $<0.001$ \\
\hline Obesity & 0.961 & $0.948-0.975$ & $<0.001$ \\
\hline
\end{tabular}


$(1,499,252$; all subjects admitted to internal medicine departments in Spain during 9 years with a diagnosis of T2DM). Among this population we identified 199,871 $(13.3 \%)$ with a diagnosis of obesity.

Our findings are similar to other studies. Doehner, et al. [18] from the original PROactive study population, included 5,202 patients (99.3\%) with enough weight measurements to be included in their analysis concluding that among patients with T2DM and cardiovascular comorbidity, overweight and obese patients had a lower mortality compared to patients with normal weight. Weight loss but not weight gain was associated with increased mortality and morbidity.

Carnethon, et al. [27] in a longitudinal study, patients who had a normal weight at the time of incidental diabetes experienced higher total and non cardiovascular mortality as compared with those who were overweight or obese. Liu, et al. report in a recent work an association between body-mass index and mortality in Chinese adults with T2DM during a mean follow-up period of $7.25 \pm 1.42$-years. The risk for allcause mortality was lower in the overweight and the obese groups than in those in the normal weight and the underweight groups [37].

Logue, et al. [25] using records of 106,640 patients in Scotland assessed and U-shaped relationship between BMI (Body Mass Index) within a year after diagnosis of diabetes and subsequent mortality, with $\mathrm{BMI}$ of 25 to < $30 \mathrm{~kg} / \mathrm{m}^{2}$ associated with the lowest mortality risk > 2 years after diagnosis of diabetes.

Costanzo, et al. [38] investigated the association between body weight and prognosis in a large cohort of 10,568 patients with T2DM with a long follow up (median of 10.6 years) and found that being overweight or obese was associated with higher risk of nonfatal cardiovascular events but not mortality. The BMI associate with best survival rated from the conventional normal $\left(18.5\right.$ to $\left.24.9 \mathrm{~kg} / \mathrm{m}^{2}\right)$ to the overweight (25 to 29.9).

However, other studies do not reach the same conclusions. In a recent retrospective analysis Alexopoulos, et al. [34], investigated the impact of obesity in hospitalized patients with hyperglycemia and diabetes (72.8\% did not have diabetes) and concluded that obesity was not associated with a higher morbidity or mortality in hospitalized patients when compared to normal weight regardless of glycemic status. No 'obesity paradox' was observed in the hospital setting among patients with diabetes and hyperglycemia. Ross, et al. [20] concluded that average body weight was associated with the best survival in their cohort of 373 patients (men and women), with a J-shaped relative risk curve and a poorer survival rate for those thin, overweight or obese. Mulnier, et al. [23] in a large cohort selected from the General Practice Research Database, of 44,230 patients with
T2DM, the hazard ratio for all-cause mortality using BMI $20-24 \mathrm{~kg} / \mathrm{m}^{2}$ as the reference range, was 1.43 for those with BMI $35-54 \mathrm{~kg} / \mathrm{m}^{2}$.

Tobias, et al. [26] in a 11,427 participants study observed an a J-shaped association between BMI and all-cause mortality, those in the lowest BMI (18.5 to 22.4) had a significantly elevated mortality as did those in the highest categories (30-34.9); the lowest risk observed among the normal-weight (BMI 22.5 to 24.9).

The results are discordant even among the methodologically strongest reports, because in some of them the sample is small, smoking and hypertension are not recorded, comorbid conditions were not taken, in others underweight patients were classified as normal, etc.

Our study is the first one that analyses the influence of obesity during hospitalization in medical diabetic patients. The strengths of our work are the size of the sample, we recorded key characteristics as smoking and blood pressure, considered comorbid conditions and the information was gathered from an official data base that registers all the activity of internal medicine departments in Spain.

The reason for this "obesity paradox" in patients with T2DM is unclear. Our obese patients show a higher prevalence in the association of hypertension and smoking than the normal-weight population and are also younger. These circumstances could make them visit their physician earlier and be appropriately medicated for these diseases. Compared with normalweight patients, overweight/obese patients have a better metabolic reservoir, an aspect that allows them to deal better with the systemic catabolic imbalance and impaired metabolic efficiency induced by the hospitalization [39].

Another possible explanation for the obesity paradox involves the role of adipose tissue in reducing systemic inflammation in these patients. It has been suggested that adipose tissue produces tumor necrosis factor-a (TNF-a) receptors, positively correlating with body fat levels, which act by neutralizing the harmful effects of TNF-a. Therefore, overweight and obese patients could benefit from the higher levels of these receptors, compared with normal-weight and underweight subjects [40]. An aspect to emphasize is that most studies assessing obesity and mortality have relied on BMI to define obesity. Body mass index as a measure of body composition, lacks the ability to quantify percent body fat and distinguish between lean and fat body mass. Furthermore, in diseased patients, BMI is not a sensitive marker of nutritional status, especially in patients with hyper-hydration and edema [41]. In our opinion, to establish a clear-cut relationship between obesity and cardiovascular-related mortality, other measures of obesity, especially those accounting for central obesity, such as waist circumference, waist-to-hip ratio, and 
waist-to-height ratio, which might be more accurate for cardiovascular risk stratification, should be used [9].

There is a well-established association found between obesity related DNA methylation patterns at birth and adult onset obesity and diabetes. Epigenetic markers may serve to screen individuals at risk for obesity and assess the effects of interventions in early life that may delay or prevent obesity early. This might contribute to lower the obesity-related burden of death and disability as a health measure [42].

Some potential limitations of the present study deserve comment. In our database obesity is recorded only as a diagnosis, we don't have BMI or any of the other measures of obesity. There has only been limited evaluation of how frequently obesity is actually captured in administrative databases or how accurately is captured. A recent study by Martin, et al. [43] to assess the validity of obesity coding in administrative database confirmed that obesity was poorly coded; however, when coded, it was coded accurately. Perhaps administrative databases are not an optimal data source for obesity prevalence but could be used to define obese cohorts especially in hospitalized patients. In conclusion, on the basis of the present study of patients with T2DM hospitalized in internal medicine wards in Spain trough a unique database from an integrated health-care system, we conclude that obesity appears to be associated with an important reduction in mortality during admissions and also with a reduction of readmission in the next 30 days and shorter length of stay.

The obesity paradox is a complex phenomenon that requires additional investigation and future studies should consider weight change when evaluating the longitudinal association among health, overweight/ obesity, and outcomes. It is possible that other measures of obesity besides BMI should be needed.

\section{Conflict of Interest}

The authors state that they have no conflicts of interest.

\section{Acknowledgments}

The authors thank the Spanish Minister of Health for the permission to obtain of the data.

\section{References}

1. Horwich TB, Fonarow GC, Hamilton MA, MacLellan WR, Woo MA, et al. (2001) The relationship between obesity and mortality in patients with heart failure. J Am Coll Cardiol 38: 789-795.

2. Curtis JP, Selter JG, Wang Y, Rathore SS, Jovin IS, et al. (2005) The obesity paradox: body mass index and outcomes in patients with heart failure. Arch Intern Med 165: 55-61.

3. Kenchaiah S, Pocock SJ, Wang D, Finn PV, Zornoff LA, et al. (2007) Body mass index and prognosis in patients with chronic heart failure: insights from the Candesartan in Heart failure: Assessment of Reduction in Mortality and morbidity (CHARM) program. Circulation 116: 627-636.

4. Bogers RP, Bemelmans WJ, Hoogenveen RT, Boshuizen HC, Woodward M, et al. (2007) Association of overweight with increased risk of coronary heart disease partly independent of blood pressure and cholesterol levels: a meta-analysis of 21 cohort studies including more than 300 000 persons. Arch Intern Med 167: 1720-1728.

5. Adams KF, Schatzkin A, Harris TB, Kipnis V, Mouw T, et al. (2006) Overweight, obesity, and mortality in a large prospective cohort of persons 50 to 71 years old. N Engl J Med 355: 763-778.

6. Fonarow GC, Srikanthan P, Costanzo MR, Cintron GB, Lopatin M, et al. (2007) An obesity paradox in acute heart failure: analysis of body mass index and inhospital mortality for 108,927 patients in the Acute Decompensated Heart Failure National Registry. Am Heart J 153: 74-81.

7. Oreopoulos A, Padwal R, Kalantar Zadeh K, Fonarow GC, Norris CM, et al. (2008) Body mass index and mortality in heart failure: a meta-analysis. Am Heart J 156: 13-22.

8. Vemmos K, Ntaios G, Spengos K, Savvari P, Vemmou A, et al. (2011) Association between obesity and mortality after acute first-ever stroke: the obesity-stroke paradox. Stroke 42: 30-36.

9. Barba R, Marco J, Ruiz J, Canora J, Hinojosa J, et al. (2015) The obesity paradox in stroke:Impact on mortality and short-term readmission. J Stroke Cerebrovas Dis 24: 766-770.

10. Romero Corral A, Montori VM, Somers VK, Korinek J, Thomas RJ, et al. (2006) Association of bodyweight with total mortality and with cardiovascular events in coronary artery disease: a systematic review of cohort studies. Lancet 368: 666-678.

11. Kalantar Zadeh K, Kuwae N, Wu DY, Shantouf RS, Fouque D, et al. (2006) Associations of body fat and its changes over time with quality of life and prospective mortality in hemodialysis patients. Am J Clin Nutr 83: 202-210.

12. Agarwal R, Bills JE, Light RP (2010) Diagnosing obesity by body mass index in chronic kidney disease: an explanation for the "obesity paradox?" Hypertension 56: 893-900.

13. Mitja Lainscak, Stephan von Haehling, Wolfram Doehner, Irena Sarc, Tina Jeric, et al. (2011) Body mass index and prognosis in patients hospitalized with acute exacerbation of chronic obstructive pulmonary disease. J Cachexia Sarcopenia Muscle 2: 81-86.

14. Zapatero A, Barba R, Ruiz J, Losa JE, Plaza S, et al. (2013) Malnutrition and obesity: influence in mortality and readmissions in chronic obstructive pulmonary disease patients. J Hum Nutr Diet 26: 16-22.

15. Navarro WH, Loberiza FR Jr, Bajorunaite R, van Besien $\mathrm{K}$, Vose JM, et al. (2006) Effect of body mass index on mortality of patients with lymphoma undergoing autologous hematopoietic cell transplantation. Biol Blood Marrow Transplant 12: 541-551.

16. Escalante A, Haas RW, del Rincón I (2005) Paradoxical effect of body mass index on survival in rheumatoid arthritis: role of comorbidity and systemic inflammation. Arch Intern Med 165: 1624-1629.

17. McEwen LN, Kim C, Karter AJ, Haan MN, Ghosh D, et al. (2007) Risk factors for mortality among patients with diabetes: the Translating Research Into Action for Diabetes (TRIAD) Study. Diabetes Care 30: 1736-1741. 
18. Doehner W, Erdmann E, Cairns R, Clark AL, Dormandy JA, et al. (2012) Inverse relation of body weight and weight change with mortality and morbidity in patients with type 2 diabetes and cardiovascular co-morbidity: an analysis of the PROactive study population. Int J Cardiol 162: 20-26.

19. B Balkau, E Eschwège, L Papoz, JL Richard, JR Claude, et al. (1993) Risk factors for early death in non-insulin dependent diabetes and men with known glucose tolerance status. BMJ 307: 295-299.

20. Ross C, Langer RD, Barrett-Connor E (1997) Given diabetes, is fat better than thin? Diabetes Care 20: 650-652.

21. Chaturvedi N, Fuller JH (1995) Mortality risk by body weight and weight change in people with NIDDM. The WHO Multinational Study of Vascular Disease in Diabetes. Diabetes Care 18: 766-774.

22. Zoppini G, Verlato G, Leuzinger C, Zamboni C, Brun E, et al. (2003) Body mass index and the risk of mortality in type II diabetic patients from Verona. Int $\mathrm{J}$ Obes Relat Metab Disord 27: 281-285.

23. Mulnier HE, Seaman HE, Raleigh VS, Soedamah-Muthu SS, Colhoun HM, et al. (2006) Mortality in people with type 2 diabetes in the UK. Diabet Med 23: 516-521.

24. Khalangot M, Tronko M, Kravchenko V, Kulchinska J, Hu G (2009) Body mass index and the risk of total and cardiovascular mortality among patients with type 2 diabetes: a large prospective study in Ukraine. Heart 95: 454-460.

25. Jennifer Logue, Jeremy J Walker, Graham Leese, Robert Lindsay, John McKnight, et al. (2013) Association between BMI measured within a year after diagnosis of type 2 diabetes and mortality. Diabetes Care 36: 887-893.

26. Deirdre K Tobias, An Pan, Chandra L Jackson, Eilis J O'Reilly, Eric L Ding, et al. (2014) Body-mass index and mortality among adults with incident type 2 diabetes. $\mathrm{N}$ Engl J Med 370: 233-244.

27. Carnethon MR, De Chavez PJ, Biggs ML, Lewis CE, Pankow JS, et al. (2012) Association of weight status with mortality in adults with incident diabetes. JAMA 308: 581 590.

28. Sasaki A, Horiuchi N, Hasegawa K, Uehara M (1989) Mortality and causes of death in type 2 diabetic patients. $A$ long-term follow-up study in Osaka District, Japan. Diabetes Res Clin Pract 7: 33-40.

29. McAuley PA, Myers JN, Abella JP, Tan SY, Froelicher VF, et al. (2007) Exercise capacity and body mass as predictors of mortality among male veterans with type 2 diabetes. Diabetes Care 30: 1539-1543.

30. Marina Verçoza Viana, Rafael Barberena Moraes, Amanda Rodrigues Fabbrin, Manoella Freitas Santos, Vanessa Bielefeldt Leotti Torman, et al. (2014) Contrasting effects of preexisting hyperglycemia and higher body size on hospital mortality in critically ill patients: a prospective cohort study. BMC Endocr Disord 14: 50.
31. Clark AL, Fonarow GC, Horwich TB (2015) Impact of cardiorespiratory fitness on the obesity paradox in patients with systolic heart failure. Am J Cardiol 115: 209-213.

32. Hutagalung R, Marques J, Kobylka K, Zeidan M, Kabisch B, et al. (2011) The obesity paradox in surgical intensive care unit patients. Intensive Care Med 37: 1793-1799.

33. Stamou SC, Nussbaum M, Stiegel RM, Reames MK, Skipper ER, et al. (2011) Effect of body mass index on outcomes after cardiac surgery: is there an obesity paradox? Ann Thorac Surg 91: 42-47.

34. Anastasia Stefania Alexopoulos, Maya Fayfman, Liping Zhao, Jeff Weaver, Lauren Buehler, et al. (2016) Impact of obesity on hospital complications and mortality in hospitalized patients with hyperglycemia and diabetes. BMJ Open Diabetes Res Care 4.

35. Charlson ME, Pompei P, Ales KL, MacKenzie CR (1987) A new method of classifying prognostic comorbidity in longitudinal studies: development and validation. J Chronic Dis $40: 373-383$.

36. Deyo RA, Cherkin DC, Ciol MA (1992) Adapting a clinical comorbidity index for use with ICD-9-CM administrative databases. J Clin Epidemiol 45: 613-619.

37. Liu H, Wu S, Li Y, Sun L, Huang Z, et al. (2017) Body mass index and mortality in patients with type 2 diabetes mellitus: A prospective cohort study of 11,449 participants. J Diabetes Complications 31: 328-333.

38. Costanzo P, Cleland JG, Pellicori P, Clark AL, Hepburn $D$, et al. (2015) The obesity paradox in type 2 diabetes mellitus: relationship of body mass index to prognosis: a cohort study. Ann Intern Med 162: 610-618.

39. Ovbiagele B, Bath PM, Cotton D, Vinisko R, Diener HC (2011) Obesity and recurrent vascular risk after a recent ischemic stroke. Stroke 42: 3397-3402.

40. Kastorini CM, Panagiotakos DB (2012) The obesity paradox: methodological considerations based on epidemiological and clinical evidence--new insights. Maturitas 72: 220-224.

41. Campillo B, Paillaud E, Uzan I, Merlier I, Abdellaoui M, et al. (2004) Value of body mass index in the detection of severe malnutrition: influence of the pathology and changes in anthropometric parameters. Clin Nutr 23: 551-559.

42. Pinney SE, Simmons RA (2010) Epigenetic mechanisms in the development of type 2 diabetes. Trends Endocrinol Metab 21: 223-229.

43. Billie Jean Martin, Guanmin Chen, Michelle Graham, Hude Quan (2014) Coding of obesity in administrative hospital discharge abstract data: accuracy and impact for future research studies. BMC Health Serv Res 14: 70. 